\title{
Price and Service Competition with Maintenance Service Bundling
}

\author{
Yi Wang ${ }^{a} \quad$ Linyan $\operatorname{Sun}^{b}$ Rong $\mathrm{Qu}^{c} \quad$ Gang $\mathrm{Li}^{b}$ \\ ${ }^{a}$ Department of Industrial Engineering \\ School of Management, Hangzhou Dianzi University \\ Hangzhou, 310018, China \\ wangyi029@gmail.com \\ ${ }^{b}$ Department of Industrial Engineering \\ School of Management, Xi'an Jiaotong University \\ Xi'an, 710049, China \\ lysun@mail.xjtu.edu.cn glee@mail.xjtu.edu.cn
}
${ }^{c}$ Automated Scheduling Optimization and Planning Group, School of Computer Science
University of Nottingham
Nottingham NG8 1BB, UK
rxq@cs.nott.ac.uk

\begin{abstract}
In many equipment manufacturing industries, firms compete with each other not only on products price, but also on maintenance service. More and more traditional products oriented firms are offering their customers products bundled with maintenance service (P\&S bundles). In this study, we examine firms' incentive to offer customers products bundling with long-term maintenance or repair support service in a duopoly competitive environment. When providing $\mathrm{P} \& \mathrm{~S}$ bundles, a firm need to determine the service level (in terms of average response time guarantee for the service in this paper) to offer and needs to build a service facility to handle the maintenance service requirements. Based on the analysis of three sub-game models, we characterize the market conditions in which only one firm, both firms or neither firm will offer P\&S bundles. Finally, we analyze the affects of serval market factors on firms' strategy choices. Keywords: Service Competition, Queues, Products and service bundles, Product differentiation.
\end{abstract}




\section{Introduction}

The rapid growth of business is forcing more and more traditional product oriented firms to bundle their products with maintenance service. Rolls Royce, for example, offers their customers a lifelong car repair service. They set-up a world wide service system so customers' repairing service requirements can always be processed almost all over the world. For customers, the bundled service can increase their satisfaction by reducing the burdens of using it. By offering P\&S bundles to customers, firms may increase their market share and (or) earn additional revenue from the bundled service.

Although firms may benefit a lot from bundling products with service, they need to invest intensively on service facility to process service requests from customers. To make strategic decisions on whether to offer P\&S bundles, firms need to carefully balance the benefits and cost incurred. A number of challenging decisions include: the service level to offer, the price to charge and the capacity of service facility.

To better understand firms' strategic decisions on service bundling, in this paper we address the following research questions: First, under what market conditions should firms offer P\&S bundles or just products alone to customers? Second, if it is better to offer P\&S bundles, what is the optimal service level to offer? Finally, what are the effects of different market factors on firms' service level decisions?

We consider a duopoly wherein both firms have the choices of offering P\&S bundles which creates new benefit of service for customers but also incurs service capacity cost, or just products alone. By constructing a game theory model, we examine two firms' bundling strategy choices and the price/service level decisions. In this paper, we observe the following key management insights: First, we found that a higher differentiation between firms' products reduces the service level offered by $P \& S$ bundle providers. Second, due to the economics of scale in service capacity investment, P\&S bundle providers intend to offer a higher service level when the market size is larger. Third, when there is only one firm offering $\mathrm{P} \& \mathrm{~S}$ bundles, it will offer a higher service level and charge a higher price than when both firms offer P\&S bundles. Finally, we found whether firms will offer P\&S bundles or products alone depends on the cost of the service capacity, the attractiveness of the service to customers and the market size.

The rest of this paper is organized as follows: The next section reviews the related literature. We present our model in section 3. In section 4, we analyze the decisions under different subgames and characterize the main strategy equilibrium results. Several numerical experiments are 
presented in section 5 to examine the impacts of the service level sensitivity, the firms difference and the market size in the equilibrium strategies. We conclude in section 6 . All the proofs omitted in the text are presented in the Appendix.

\section{Literature Review}

The bundling problem has been investigated by many researchers from different viewpoints. Stigler (1968) first discussed the benefit of bundling and showed how it could increase profits when consumer valuations for goods were negatively correlated. Based on an extensive review, Stremersch and Tellis (2002) defined terms and identified two key dimensions in bundling: (1) whether the focus of bundling is on the price or product; (2) whether the form of bundling is pure or mixed. Carbajo, DeMeza, and Seidmann (1990) showed that the profitability of bundling depends on the nature of product market competition. Bundling is profitable because it reduces the price competition. Chen (1997) offered an equilibrium theory of product bundling by competing firms, and demonstrated the potential of using bundling as a facilitating device in a competitive market to help firms to avoid direct price competition. Furthermore, Nalebuff (2004) showed that bundling is an effective strategy for the bundles provider to prevent their rival with only part of the bundles entering the market. Research on bundling competition mainly focused on the price competition, few studies have investigated the service level decision issues on the bundling of products and service. In our paper, we study the bundling of products and service, as well as the service level decisions.

Our work is also related to the literature of service industry competition. Luski (1976) firstly studied the competition between service providers in queueing systems. They addressed a duopoly where each of the firms acts as an $\mathrm{M} / \mathrm{M} / 1$ system, where customers select their service provider based on the full price and the expected steady state waiting time. Levhari and Luski (1978) extended this model by assuming that the cost rates among customers are independent and identically distributed. However the existence of equilibrium in these models is still an open question. Chen and Wan (2000) also studied the model of Luski (1976), and showed there exists a price equilibrium for the basic model with a uniform cost rate. Allon and Federgruen (2007) studied price and service level competition between oligopolistic firms. They defined a firm's service level as the difference between an upper bound benchmark for the standard waiting time and the firm's actual waiting time. Allon and Federgruen (2008) investigated the service competition in service industry. Assuming that the capacity cost is proportional to the service rates, they showed how the competitive behavior depends on the characteristics of queueing systems from the service providers. Zhang eta. (2009) studied the service level and price competition between two web service providers 
offering functionally the same web services. They analyzed both cases of simultaneously decision, and sequential-move situation. These papers mostly focused on the service competition in service industry, and did not consider the service competition in products oriented industry.

As industries are changing from product-centric to service-centric strategies, there is an increasing interest towards the research of service competition in product-oriented industries. Cohen and Whang (1997) studied the strategic problem of manufacturers who design bundles for a product which may require maintenance service after sale. They focused on the service competition between the manufacturer and other service providers. Xiao and Yang (2008) built a price-service competition model of two supply chains under demand uncertainty. Their result suggested that a retailer's optimal retail price and service level are negatively related to their rival's service investment efficiency. Fan, Kumara and Whinston (2009) used a game theory approach to analyze the problem of bundling software with a delivery and maintenance service. They studied the price and quality competition between a SWS (traditional shrink-wrap software) provider and a SaaS (software as a service) provider and showed that the cost along with quality affect the equilibrium. Kurata and Nam (2010) analyzed the after-sales service decisions in a two-stage supply chain, where manufacturer offers base after-sales service and retailer offers optional after-sales service. They found that after-sales service plans that are determined to maximize profits do not match optimal after-sales service levels that can satisfy customers the most. Kameshwaran eta.(2009) studied the problem of bundling product and after-sales service together in a competition environment. Their game theoretic model analyzed firms' three strategy choices: offering product only, product and service independently, or product and service bundled. Their model focused on the price competition and did not consider the service competition. These papers, with the exception of Kameshwaran eta. (2009), do not consider the firms' strategy choices on whether or not to bundle their products with service. Our paper contributes to this stream of studies by considering firms' strategy choices on whether or not to offer products and service bundles.

\section{Model Formulation}

We consider a model where two symmetric firms (Firm 1 and Firm 2) are competing in a market with $M$ customers. Each firm offers a type of products which can be bundled with maintenance service. We assume that customers are distributed uniformly on a product line of length 1 between the two firms. A customer's location at the product line is denoted as $x \in[0,1]$, representing his preference between two firms (e.g., relative preference between the car of BMW and Benz). A customer located at the left end of the product line $(x=0)$ treats Firm 1's product as an ideal 
product, and a customer located at the right end $(x=1)$ treats Firm 2's as his favorite. The distance of a customer's location to the left (or right) end of this line, which is $x$ (or $1-x$ ), denotes the difference between the customer's ideal products from Firm 1 (or Firm 2)'s products. Each customer has only one unit of demand.

Firms can decide whether to offer P\&S bundles or products alone to customers. In the rest of this paper, we use the term "bundles" to refer to "P\&S bundles". When offering bundles, Firm $i$ needs to guarantee that a certain service level will be achieved. Following Allon and Federgruen(2008), we define the service level of bundles provider Firm $i$, denoted as $\theta_{i}$, as the difference between the expected response time $W_{i}$ and the maximum expected response time $\bar{W}\left(W_{i} \leq \bar{W}\right)$, i.e, $\theta_{i}=\bar{W}-W_{i}$. The maximum expected response time can be an industry standard required by law or a conventional upper bound.

Customers choose bundles or products of the two firms based on the price, the service level of bundles and their own products preference. Suppose that Firm 1 offers bundles with an expected response time guarantee $W_{1}$, i.e, a service level of $\theta_{1}=\bar{W}-W_{1}$, to customers at price $p_{1}$. For the customer at location $x$, the net utility of buying a bundle from Firm 1 is $U+k\left(\bar{W}-W_{1}\right)-p_{1}-t x$, where $U$ is the utility for a customer if he gets his ideal product for free (without service), and $U$ is assumed to be the same for all customers. This utility function is quite intuitive. A customer's utility is linearly increasing in the offered service level $\left(\bar{W}-W_{1}\right)$ and linearly decreasing in the charged price $p_{1}$ and the degree of difference to customer's ideal product, $x . k\left(\bar{W}-W_{1}\right)$ is the customer's utility to the bundled service, and $k$ denotes customers' sensitivity to the bundled service. When Firm 1 reduces the expected response time $W_{1}$, the utility increases because a customer's expected response time is shorter. Note that if the expected response time $W_{1}$ is larger than or equals to the maximum expected response time $\bar{W}$, the utility for service is 0 , which is indifferent from the case where no bundled service is offered. Item $t x$ represents the loss of utility because of the difference between Firm 1's products and the ideal products of a customer at $x$, where $t$ is the intensity of relative preference of firms. When $t$ is very small. e.g., $t=0$, people almost have no preference between two firms (In customers' view, these two firms has no difference). A higher $t$ implies a bigger difference between two firms. When Firm 1 offers products alone to customers at price $p_{1}$, the customer gets no service, resulting to a utility as $U-p_{1}-t x$. Similarly, when Firm 2 offers a bundle, or a product alone to a customer, the customer's utility of buying it is $U+k\left(\bar{W}-W_{2}\right)-p_{2}-t(1-x)$, or $U-p_{2}-t(1-x)$. A customer buys a product or a bundle from the firm that provides him a higher utility. In this study, we consider the case that the whole market is covered by two firms, and $U$ is assumed to be large enough so that all customers' net utility are nonnegative and all consumers will buy a product from one of the two firms. The unit 


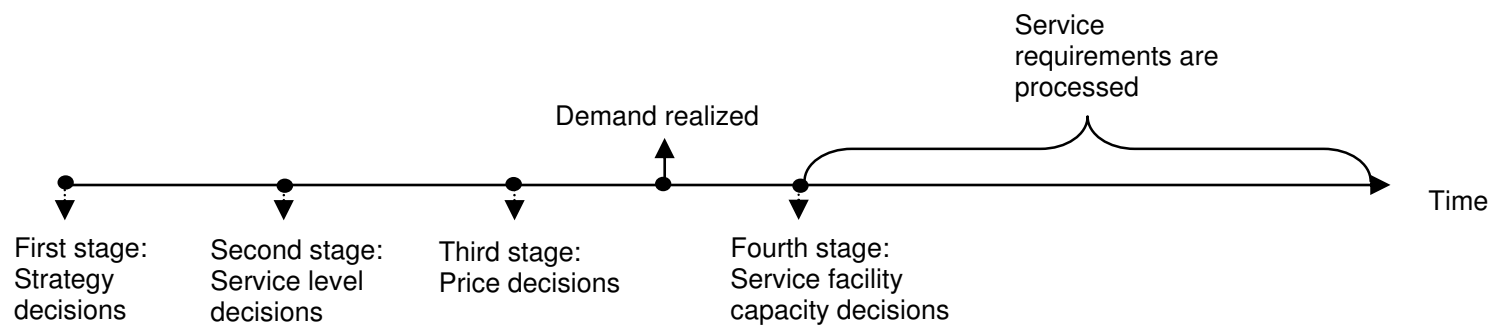

Figure 1: Time series of events

production cost for both firms' products is assumed to be $c$.

When buying bundles, customers also ask the for service level guarantee agreements. After the demands are realized, the bundles providers need to build up the corresponding service facilities (e.g. the maintenance systems or the IT service support departments) to process the service requirements. Note that the bundles providers should decide the capacity of the service facilities to guarantee the service level, i.e. the mean response time for customers' service requirement should not be larger than the promised average delay. Thus we need to consider the queuing delay and the processing rate for the service requirements.

Following Tan and Mookerjee (2005), we assume that the customers' service requirements arrival at Firm $i$ follow a Poisson process with a mean arrival rate $\lambda_{i}$. Notice that a service requirement is just raised by a customer who bought a $\mathrm{P} \& \mathrm{~S}$ bundle. It is naturally to assume that $\lambda_{i}$ is proportional to the demand $D_{i}$, i.e., $\lambda_{i}=\frac{D_{i}}{n}$, where $\frac{1}{n}$ is the average usage rate of all customers. As the processing time of most service are closer to exponential distribution, we assume that the service requirement processing time here is exponentially distributed. We use the service processing rate $\mu_{i}$ to represent the service capacity of Firm $i$. Obviously, a higher service capacity could provide a higher service processing rate. Following Allon and Federgruen(2008), we assume that the capacity cost is proportional to the service rates, i.e., each unit of service capacity incurs a cost of $c_{v}$. Thus the total cost for the service capacity is $c_{v} \mu_{i}$ for Firm $i$. We analyze later the firms' optimal capacity decisions for given expected waiting time guarantees and realized demand.

We consider a four-stage game. The sequence of all events in the procedure is shown in Figure 1. At the first stage, both firms decide whether to offer bundles or products alone. We denote the first stage strategy of Firm $i, i \in\{1,2\}$, as $S_{i} \in\{\mathrm{B}, \mathrm{P}\}$, where B represents the decision to offer bundles, and $\mathrm{P}$ represents the decision to only offer products alone, respectively. We use $\left(S_{1}, S_{2}\right)$ to denote the outcome of the first stage strategy. If any of them decide to offer bundles, they set the 
service level at the second stage. At the third stage, given the strategy decisions $\left(S_{1}, S_{2}\right)$ and the service level decisions (if applicable), both firms determine the price for the bundles or products alone. After the the price decision, the demand is realized. At the final stage, firms determine the capacity of service facilities (if applicable) to build up. Then all the service requirements arrive and are processed in droves (if applicable).

\section{Equilibrium Analysis}

Because each firm can decide whether to offer bundles or products alone at the first stage, we analyse the following sub-games induced by the outcomes of the first stage before analyzing the overall game strategy: (1) both firms offer products alone, denoted as (P, P); (2) both firms offer bundles, denoted as (B, B); (3) Firm 1 offers bundles and Firm 2 offers products alone, denoted as (B, P). (4) Firm 1 offers products alone and Firm 2 offers bundles, denoted as (P, B). In this model, we assume that two firms are symmetric. Thus it is sufficient to just analyze the first three scenarios. The outcome of the $(\mathrm{P}, \mathrm{B})$ sub-game can be easily derived from the $(\mathrm{B}, \mathrm{P})$ sub-game. Using standard backward induction, we first consider the firms' service capacity decisions at the fourth stage.

\subsection{Service Capacity Decisions}

If Firm $i$ offers bundles to customers, the service requirements and the service facility of Firm $i$ constructs a M/M/1 queuing system. In this queuing system, the expected waiting time for a customer's service requirement is $w_{i}=\frac{1}{\mu_{i}-\lambda_{i}}$. Therefore, given the average service response time guarantee $W_{i}$ and the demand $D_{i}$, the decision problem of Firm $i$ 's service capacity is defined as follows:

$$
\begin{gathered}
\min _{\mu_{i}} c_{v} \mu_{i} \\
\text { s.t } \quad: \quad \frac{1}{\mu_{i}-\frac{D_{i}}{n}} \leq W_{i} .
\end{gathered}
$$

It is easy to see that the optimal capacity is as follows:

$$
\mu_{i}=\frac{1}{W_{i}}+\frac{D_{i}}{n}
$$


When Firm $i$ decides to offer bundles, the capacity cost incurred is: $\frac{c_{v}}{W_{i}}+\frac{c_{v} D_{i}}{n}$. The constant $\operatorname{cost} \frac{c_{v}}{W_{i}}$ is independent to demand $D_{i}$, and a variable cost of $\frac{c_{v} D_{i}}{n}$ is proportional to the demand. Note that for a given service level decision and a realized demand, the cost of service capacity is sunk.

\section{$4.2(\mathrm{P}, \mathrm{P})$ Sub-game}

When both firms decide to provide products alone to customers at the first stage, they just need to determine the prices. From the utility function, we can see that a customer located at $x$ is indifferent between the two firm's products iff:

$$
U-p_{1}-t x=U-p_{2}-t(1-x) .
$$

We can thus derive from equation (3) that the customer's location is $\bar{x}^{<P, P>}=\frac{p_{2}-p_{1}+t}{2 t}$. Those customers whose locations are at the left to $\bar{x}^{<P, P>}$, i.e. $x \leq \bar{x}^{<P, P>}$, will buy products from Firm 1, and the other customers will choose Firm 2's products. The demand functions of the two firms are $D_{1}=\left(\frac{p_{2}-p_{1}+t}{2 t}\right) M$ and $D_{2}=\left(1-\frac{p_{2}-p_{1}+t}{2 t}\right) M$.

Back to the pricing decision stage, two firms determine the price to maximize:

$$
\begin{gathered}
\pi_{1}^{<P, P>}=\left(p_{1}-c\right)\left(\frac{p_{2}-p_{1}+t}{2 t}\right) M \\
\pi_{2}^{<P, P>}=\left(p_{2}-c\right)\left(1-\frac{p_{2}-p_{1}+t}{2 t}\right) M
\end{gathered}
$$

Using first order conditions for the pricing problem in (4) and (5), we can obtain the equilibrium solutions in sub-game $(\mathrm{P}, \mathrm{P})$, which are presented in Proposition 1.

Proposition 1 If both firms choose to provide products alone to customers at the first stage, the equilibrium prices are: $p_{1}^{<P, P>}=p_{2}^{<P, P>}=c+t$, and the equilibrium profits are: $\pi_{1}^{<P, P>}=$ $\pi_{2}^{<P, P>}=\frac{M t}{2}$.

In subgame $(\mathrm{P}, \mathrm{P})$, both firms charge the same price that exceeds unit production cost $c$ by $t$. While $t$ represents the difference between two firms' products, they can charge a higher price when $t$ is larger. This is in accordance with the conclusion of prior literature (i.e., Daniel 2001) that the differentiation between two firms reduces the intensity of competition. Daniel (2001) showed the same result in an imperfect competition model. The expected profits of two firms are the same and increase with the market size $M$ and $t$. Thus a larger market size or bigger difference between two firms will lead to higher expected profits. 


\section{3 (B, B) Sub-game}

When both firms choose to offer bundles to customers at the first stage, a customer located at $x$ is indifferent between two firms' bundles iff:

$$
U+k\left(\bar{W}-W_{1}\right)-p_{1}-t x=U+k\left(\bar{W}-W_{2}\right)-p_{2}-t(1-x) .
$$

By solving equation (6), we can derive the indifferent customer's location

$$
\bar{x}^{<B, B>}=\frac{k\left(W_{2}-W_{1}\right)+p_{2}-p_{1}+t}{2 t} .
$$

Since we are interested in a more general case when both firms are in the market, we impose a condition $\bar{x}^{<B, B>} \in[0,1]$, which requires the assumption $k \bar{W} \leq t<3 t$, i.e. the difference between the two firms is sufficiently large. Consequently, customers in the interval $\left[0, \bar{x}^{<B, B>}\right]$ will purchase bundles from Firm 1, while those in the interval $\left[\bar{x}^{<B, B>}, 1\right]$ will purchase bundles from Firm 2. The demand for two firms are $D_{1}^{<B, B>}=\left[\frac{k\left(W_{2}-W_{1}\right)+p_{2}-p_{1}+t}{2 t}\right] M$ and $D_{2}^{<B, B>}=$ $\left[\frac{k\left(W_{1}-W_{2}\right)+p_{1}-p_{2}+t}{2 t}\right] M$.

Given Firm $i$ ' expected response time guarantee $W_{i}$ and price decisions $p_{i}$, the demand of Firm $i$ can be identified. From (2), we can see that the service capacity decision of Firm $i$ at the fourth stage is $\mu_{i}^{<B, B>}=\frac{1}{W_{i}}+\frac{D_{i}^{<B, B>}}{n}$.

The profit function of firm $i$ in the sub-game $(\mathrm{B}, \mathrm{B})$ is $\pi_{1}^{<B, B>}=\left(p_{1}-c\right) D_{i}^{<B, B>}-\frac{c_{v}}{n} D_{i}^{<B, B>}-$ $\frac{c_{v}}{W_{i}}$. Given $W_{1}$ and $W_{2}$, two firms determine the prices to maximize their profits at the third stage. By substituting the service capacity decisions into two firms' profit functions and simplification, we can get:

$$
\begin{aligned}
& \pi_{1}^{<B, B>}=\left(p_{1}-c-\frac{c_{v}}{n}\right)\left[\frac{k\left(W_{2}-W_{1}\right)+p_{2}-p_{1}+t}{2 t}\right] M-\frac{c_{v}}{W_{1}} \\
& \pi_{2}^{<B, B>}=\left(p_{2}-c-\frac{c_{v}}{n}\right)\left[\frac{k\left(W_{1}-W_{2}\right)+p_{1}-p_{2}+t}{2 t}\right] M-\frac{c_{v}}{W_{2}}
\end{aligned}
$$

Using the first order conditions, we can derive the optimal prices as follows:

$$
p_{1}^{<B, B>}=c+\frac{c_{v}}{n}+t+\frac{k\left(W_{2}-W_{1}\right)}{3}
$$




$$
p_{2}^{<B, B>}=c+\frac{c_{v}}{n}+t+\frac{k\left(W_{1}-W_{2}\right)}{3}
$$

Now we analyze two firms' service level decisions at the second stage. By substituting (9) and (10) into (7) and (8), we get

$$
\begin{aligned}
& \pi_{1}^{<B, B>}=\frac{M}{2 t}\left[t+\frac{k\left(W_{2}-W_{1}\right)}{3}\right]^{2}-\frac{c_{v}}{W_{1}} \\
& \pi_{2}^{<B, B>}=\frac{M}{2 t}\left[t+\frac{k\left(W_{1}-W_{2}\right)}{3}\right]^{2}-\frac{c_{v}}{W_{2}}
\end{aligned}
$$

Using the first order conditions, we can solve the equilibrium service level decisions. Then we can further derive all equilibrium solutions of sub-game $(B, B)$, which are summarized in the following proposition.

Proposition 2 If both firms choose to provide PESS bundles to customers, the equilibrium expected response time guarantees are given by:

$$
W_{1}^{<B, B>}=W_{2}^{<B, B>}=\sqrt{\frac{3 c_{v}}{k M}}
$$

the equilibrium prices are given by:

$$
p_{1}^{<B, B>}=p_{2}^{<B, B>}=c+\frac{c_{v}}{n}+t
$$

the equilibrium service capacity decisions are given by:

$$
\mu_{1}^{<B, B>}=\mu_{2}^{<B, B>}=\sqrt{\frac{k M}{3 c_{v}}}+\frac{M}{2 n}
$$

and the equilibrium profits are given by:

$$
\pi_{1}^{<B, B>}=\pi_{2}^{<B, B>}=\frac{M t}{2}-\sqrt{\frac{c_{v} k M}{3}}
$$

From Proposition 2, we have the following observations. The equilibrium expected response time guarantees increase along the service capacity cost $c_{v}$, but the increasing rate is decreasing. Thus, as the cost for the service capacity goes down, the bundles provider could build more service capacity to offer a higher service level or a shorter expected response time guarantee. Besides, the equilibrium expected response time is decreasing in customers' sensitivity to service level $k$. As we could expect, the higher customers value the service, the higher the service level (the shorter 
expected response time guarantee) the bundles provider may offer. The equilibrium expected response time is decreasing in the market size $M$. As the market size increases, the fixed cost for the service capacity can be shared by more customers, and thus the bundles provider can afford to build more capacity and offer a higher service level. Since the service capacity decisions are determined by the service level and the demand, it is naturally to see that the optimal service capacity is decreasing in service capacity cost and increasing in market size. While $\frac{1}{n}$ is the average usage rate of all customers, a lower $n$ implies more service requirements, which requires more service capacity. Thus, the optimal service capacity is also decreasing in $n$.

To ensure both firms have the motivation to offer bundles, we assume that each customer's utility for the service is not less than the variable service cost incurred in sub-game (B, B). Specifically, we assume $k\left(\bar{W}-W_{i}^{<B, B>}\right)=k\left(\bar{W}-\sqrt{\frac{3 c_{v}}{k M}}\right) \geq \frac{c_{v}}{n}$. To justify this assumption, we check the firms' decisions in the case of $k\left(\bar{W}-\sqrt{\frac{3 c_{v}}{k M}}\right)<\frac{c_{v}}{n}$. Because the utility of bundled service is $k(\bar{W}-W)$ and the disutility of price is $-p$, we can see that without reducing customers' utility, firms would rather cut the price by $\frac{c_{v}}{n}$ than to offer bundled service, which incurres cost more than $k\left(\bar{W}-\sqrt{\frac{3 c_{v}}{k M}}\right)$. Thus firms will not offer bundles in this case.

\section{4 (B, P) Sub-game}

Suppose Firm 1 offers bundles while Firm 2 chooses to offer only products to customers at the first stage. In this case, a customer located at $x$ will be indifferent to purchasing bundles from Firm 1 or purchasing products from Firm 2 iff:

$$
U+k\left(\bar{W}-W_{1}\right)-p_{1}-t x=U-p_{2}-t(1-x) .
$$

The indifferent customers' location is: $\bar{x}^{<B, P>}=\frac{k\left(\bar{W}-W_{1}\right)+p_{2}-p_{1}+t}{2 t}$. Hence, the customers located at $\left[0, \bar{x}^{<B, P>}\right]$ will purchase bundles from Firm 1 , the customers located at $\left[\bar{x}^{<B, P>}, 1\right]$ will only purchase products from Firm 2. The demand of two firms are as follows:

$$
\begin{aligned}
& D_{1}^{<B, P>}=\left[\frac{p_{2}-p_{1}+t+k\left(\bar{W}-W_{1}\right)}{2 t}\right] M \\
& D_{2}^{<B, P>}=\left[\frac{p_{1}-p_{2}+t-k\left(W_{1}-\bar{W}\right)}{2 t}\right] M .
\end{aligned}
$$


In the sub-game (B, P), only Firm 1 has to invest in service capacity. From (2), we know that for a given expected response time guarantee $W_{1}$ and realized demand $D_{1}^{<B, P>}$, the service capacity decision of Firm 1 at the fourth stage is $\mu_{1}^{<B, P>}=\frac{1}{W_{1}}+\frac{D_{1}^{<B, P>}}{n}$.

At the third stage, Firm 1 determines price to maximize

$$
\begin{aligned}
\pi_{1}^{<B, P>}= & \left(p_{1}-c\right)\left[\frac{k\left(\bar{W}-W_{1}\right)+p_{2}-p_{1}+t}{2 t}\right] M \\
& -\frac{c_{v}}{n}\left[\frac{k\left(\bar{W}-W_{1}\right)+p_{2}-p_{1}+t}{2 t}\right] M-\frac{c_{v}}{W_{1}}
\end{aligned}
$$

Where $\frac{c_{v}}{n}\left[\frac{k\left(\bar{W}-W_{1}\right)+p_{2}-p_{1}+t}{2 t}\right] M+\frac{c_{v}}{W_{1}}$ represents the service capacity cost.

Firm 2 does not need to determine the service level decision and service capacity decision. At the third stage, Firm 2 determines the price $p_{2}$ to maximize:

$$
\pi_{2}^{<B, P>}=\left(p_{2}-c\right)\left[\frac{p_{1}-p_{2}+t}{2 t}-\frac{k\left(W_{1}-\bar{W}\right)}{2 t}\right] M .
$$

The equilibrium prices for a given $W_{1}$ are:

$$
\begin{aligned}
& p_{1}^{<B, P>}=c+t+\frac{2 c_{v}}{3 n}+\frac{k\left(\bar{W}-W_{1}\right)}{3} \\
& p_{2}^{<B, P>}=c+t+\frac{c_{v}}{3 n}-\frac{k\left(\bar{W}-W_{1}\right)}{3} .
\end{aligned}
$$

Equation (22) shows that the price of Firm 1's bundles is decreasing in the expected response time guarantee. Thus Firm 1 could charge a higher price when a shorter expected response time guarantee is offered. Equation (23) shows that the price of Firm 2's products is increasing in Firm 1 's expected response time guarantee. As Firm 1 provides a shorter $W_{1}$ (in turn, a higher service level), Firm 2 will offer a lower price to stay competitive.

Back to the second stage, only bundles provider Firm 1 need to determine the expected response time guarantee. By substituting (22) and (23) into (20), and simplification, Firm 1's profit function can be rewritten as :

$$
\pi_{1}^{<B, P>}=\frac{M t}{2}\left[1-\frac{c_{v}}{3 n t}+\frac{k\left(\bar{W}-W_{1}\right)}{3 t}\right]^{2}-\frac{c_{v}}{W_{1}}
$$


The first order condition leads to the following equation:

$$
\left(W_{1}\right)^{2}\left[\frac{3 t-\frac{C_{v}}{n}}{k}+\left(\bar{W}-W_{1}\right)\right]-\frac{9 c_{v} t}{M k^{2}}=0
$$

To characterize the equilibrium service level decision, we need the following Lemma.

Lemma 1 If $k\left(\bar{W}-\sqrt{\frac{3 c_{v}}{k M}}\right) \geq \frac{c_{v}}{n}>0$, there exists a unique value for $W_{1}^{<B, P>} \in\left(0, \bar{W}-\frac{c_{v}}{k n}\right]$, such that:

$$
\left(W_{1}^{<B, P>}\right)^{2}\left[\frac{3 t-\frac{c_{v}}{n}}{k}+\left(\bar{W}-W_{1}^{<B, P>}\right)\right]-\frac{9 c_{v} t}{M k^{2}}=0
$$

Note that without decreasing customers' utility, it is more cost saving to decrease price by $\frac{c_{v}}{n}$ than to offer bundled service with expected response time guarantee $W_{1}^{<B, P>}>\bar{W}-\frac{c_{v}}{k n}$ for bundles provider. Thus the optimal $W_{1}^{<B, P>}$ satisfies $W_{1}^{<B, P>} \in\left(0, \bar{W}-\frac{c_{v}}{k n}\right]$. Lemma 1 claims that there is a unique equilibrium solution for sub-game $(\mathrm{B}, \mathrm{P})$. Now we conclude the equilibrium service level solution in the following proposition:

Proposition 3 In sub-game $(B, P)$, there exists a unique optimal solution for the PES bundles provider at the second stage. The optimal $W_{1}^{<B, P>}$ is the unique solution of equation (26) in $\left[0, \bar{W}-\frac{c_{v}}{n}\right]$.

The comparative statics analysis results about the effects of various parameters on the the equilibrium service level solution are presented in Corollary 1:

Corollary 1 In sub-game $(B, P)$, the optimal $W_{1}^{<B, P>}$ is increasing in $t$ and $c_{v}$, and is decreasing in $k, n$ and $M$.

Corollary 1 shows that in the sub-game (B, P), a higher product differentiation will lead to a longer expected response time guarantee. A higher product differentiation will reduce the intensity of service competition, which is consistent with the conclusions in the product differentiation literature. A simple examination from customers' utility function shows that $k$ refers to the customer's utility about service. For a certain service level, a higher $k$ leads to a higher utility to customers, thus the bundles provider has the motivation to offer a shorter expected response time guarantee. Finally, 
the equilibrium expected response time guarantee is decreasing in the market size $M$, which is consistent with the result in section 3.2.

By substituting $W_{1}^{<B, P>}$ into the expressions of equilibrium prices and profits, we can derive the other equilibrium solutions of sub-game (B, P), which are summarized in Proposition 4.

Proposition 4 If Firm 1 offers bundles and Firm 2 offers products alone, the equilibrium prices for the two firms are:

$$
\begin{aligned}
& p_{1}^{<B, P>}=c+t+\frac{2 c_{v}}{3 n}+\frac{k\left(\bar{W}-W_{1}^{<B, P>}\right)}{3} \\
& p_{2}^{<B, P>}=c+t+\frac{c_{v}}{3 n}-\frac{k\left(\bar{W}-W_{1}^{<B, P>}\right)}{3}
\end{aligned}
$$

the equilibrium profits are:

$$
\begin{aligned}
& \pi_{1}^{<B, P>}=\frac{M t}{2}\left[1-\frac{c_{v}}{3 n t}+\frac{k\left(\bar{W}-W_{1}^{<B, P>}\right)}{3 t}\right]^{2}-\frac{c_{v}}{W_{1}^{<B, P>}} \\
& \pi_{2}^{<B, P>}=\frac{M t}{2}\left[1+\frac{c_{v}}{3 n t}-\frac{k\left(\bar{W}-W_{1}^{<B, P>}\right)}{3 t}\right]^{2}
\end{aligned}
$$

where $W_{1}^{<B, P>}$ is the unique solution of equation (26).

By analyzing how the equilibrium prices are affected by customers' sensitivity to service and the unit service capacity cost in sub-game (B, P), we obtain the following corollary.

Corollary 2 In sub-game (B, P), Firm 1's equilibrium price $p_{1}^{<B, P>}$ is increasing in $k$; Firm 2's equilibrium price $p_{2}^{<B, P>}$ is decreasing in $k$ and increasing in $c_{v}$.

Corollary 2 shows that as customers' sensitivity to service goes up, the bundles provider becomes more competitive. Hence for a higher $k$, Firm 1 can raise its price without reducing customers' total utility, while Firm 2 should decrease its price to keep competitive. As the unit service capacity cost increases, the bundles provider becomes less competitive, thus Firm 2 faces less pressure and it charges a higher price.

Comparing the equilibrium expected response time guarantees under different sub-games, we get the following corollary: 
Corollary 3 The PESS bundles provider Firm 1 will offer a shorter expected response time guarantee for service in sub-game $(B, P)$ than that in sub-game $(B, B)$, i.e., $W_{1}^{<B, P>}<W_{1}^{<B, B>}=$ $W_{2}^{<B, B>}$.

Corollary 3 implies that Firm 1 would offer a shorter expected response time guarantee for service when only Firm 1 offers bundles than the case when both firms offer bundles.

The relationship between the price and the unit service capacity cost at Firm 1 is much more complicated. We examine it in a numerical experiment (illustrated in Figure 2).

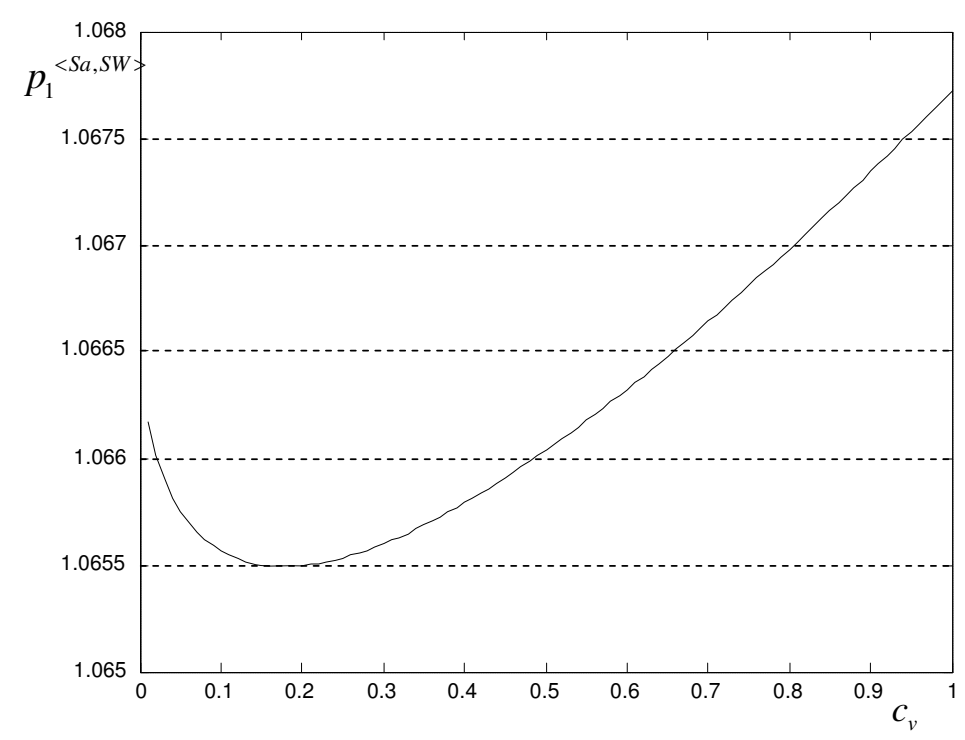

Figure 2: Relation between price $p_{1}^{<B, P>}$ and the unit service capacity cost $c_{v}$

As we can observe from Figure 2, when the unit service capacity cost is below a threshold, Firm 1 's price decreases in the unit service capacity cost. However, when the unit service capacity cost is greater than the threshold, Firm 1's price is increasing in the service capacity cost. This may be due to Firm 1's consideration of the balance between taking a bigger market share and earning a higher marginal profit. When the unit service capacity cost is low, it is more beneficial for Firm 1 to reduce its price to occupy a larger market, and as the unit service capacity cost increases, it is much more important to keep its marginal profit.

Comparing the equilibrium prices of sub-game $(\mathrm{B}, \mathrm{P})$ to those of other sub-game equilibrium solutions, we have Corollary 4.

Corollary 4 The equilibrium prices under different sub-games satisfy the following relationships: $p_{1}^{<B, P>}>p_{1}^{<B, B>}=p_{2}^{<B, B>}>p_{1}^{<P, P>}=p_{2}^{<P, P>}>p_{2}^{<B, P>}$. 
Corollary 4 shows that in sub-game (B, P), Firm 1's rival could just compete by the price, while in sub-game (B, B), Firm 1 faces both the price and service competition. As firm 1 faces less pressure in sub-game $(\mathrm{B}, \mathrm{P})$ than in sub-game $(\mathrm{B}, \mathrm{B})$, it could charge a higher price. Comparing to sub-game $(\mathrm{B}, \mathrm{B})$, two firms afford additional service capacity investment cost in sub-game (P, $\mathrm{P})$. Hence, as we could expect, the equilibrium prices in sub-game (B, B) are higher.

Corollary 3 and Corollary 4 presents an interesting result: when only one firm offers a bundle then they offer a higher service level and charge a higher price. From Corollary 2, we can see that Firm 1 charges a higher price in sub-game $(\mathrm{B}, \mathrm{P})$ than in sub-game $(\mathrm{P}, \mathrm{P})$. The marginal profit in sub-game $(\mathrm{B}, \mathrm{P})$ is $t-c_{v} / n+k(\bar{W}-W 1) / 2 t$, which is higher than the marginal profit in sub-game $(\mathrm{P}, \mathrm{P})($ just $t)$. Firm 1 can earn more marginal profit by increasing service level in sub-game (B, P). Thus we can expect that Firm 1 may offer a higher service level when only herself providing service bundles. In auto industry, most of the auto firms providing service bundles are the luxury car companies, e.g., Rolls-Royce, Lexus. These companies often offer a high level service and charge a relatively high price.

Comparing the market share of two firms under different sub-games, we have Corollary 5 .

Corollary 5 The market share under different sub-games satisfy the following relationships: $D_{1}^{<B, P>}>$ $D_{1}^{<B, B>}=D_{2}^{<B, B>}>D_{1}^{<P, P>}=D_{2}^{<P, P>}>D_{2}^{<B, P>}$.

Corollary 5 shows that Firm 1 in sub-game (B, P) got the largest market share. As in sub-game $(\mathrm{B}, \mathrm{P})$, bundles provider are more competitive than Firm 2 which does not provide service. This result intuitively sounds sense. Corollary 5 also provides an explanation to Corollary 3: when the service facility cost were shared by more customers, bundles provider may be able to offer a higher service level.

\subsection{Strategy Equilibrium}

Now we consider two firms' strategy choices at the first stage. To analyze the final strategy equilibrium, we need to compare the outputs of all sub-games at first. Let $\Delta_{1}\left(c_{v}\right)=\pi_{1}^{<B, P>}-\pi_{1}^{<P, P>}$, $\Delta_{2}\left(c_{v}\right)=\pi_{2}^{<B, P>}-\pi_{2}^{<B, B>}$. Notice that the value of $\Delta_{1}\left(\Delta_{2}\right)$ determines if Firm 1 (Firm 2) would offer bundles or products alone when Firm 2 (Firm 1) offers products alone (bundles). Thus the final strategy equilibria depends the value of $\Delta_{1}$ and $\Delta_{2}$. Lemma 2 characterizes the value of $\Delta_{1}$ and $\Delta_{2}$ over different space of $c_{v}$. 
Lemma 2 Let $\overline{c_{v}}$ be the solution of $k\left(\bar{W}-\sqrt{\frac{3 c_{v}}{k M}}\right)=\frac{c_{v}}{n}$.

(i) There exists a critical value $c_{v}^{* *} \in\left[0, \overline{c_{v}}\right]$ such that: when $c_{v}<c_{v}^{* *}, \Delta_{1}\left(c_{v}\right)>0$; when $c_{v}>c_{v}^{* *}$, $\Delta_{1}\left(c_{v}\right)<0$.

(ii) There exists a critical value $c_{v}^{*} \in\left[0, \overline{c_{v}}\right]$ such that: when $c_{v}<c_{v}^{*}, \Delta_{2}\left(c_{v}\right)<0$; when $c_{v}>c_{v}^{*}$, $\Delta_{2}\left(c_{v}\right)>0$.

(iii) $c_{v}^{*}<c_{v}^{* *}$.

Base on this result, we can show the relationship between the value of $c_{v}$ and the final equilibrium strategies.

Proposition 5 (i) if $c_{v}<c_{v}^{*}$, then $\pi_{1}^{<B, P>}>\pi_{1}^{<P, P>}, \pi_{2}^{<B, P>}<\pi_{2}^{<B, B>}$. The pure strategy Nash equilibrium is $(B, B)$ and both the firms offer bundles.

(ii) if $c_{v}^{*} \leq c_{v} \leq c_{v}^{* *}$, then $\pi_{1}^{<B, P>} \geq \pi_{1}^{<P, P>}, \pi_{2}^{<B, P>} \geq \pi_{2}^{<B, B>}$. The pure strategy Nash equilibrium is $(B, P)$ or $(B, P)$, and only one firm offers PES bundles and the other firm offers products alone.

(iii) if $c_{v}>c_{v}^{* *}$, then $\pi_{1}^{<B, P>}<\pi_{1}^{<P, P>}, \pi_{2}^{<B, P>} \geq \pi_{2}^{<B, B>}$. The pure strategy Nash equilibrium is $(P, P)$ and both firms offer products alone.

Proposition 5 has important managerial implications for firms making strategy decisions between offering bundles and products alone. As we could expect, when the unit service capacity cost is large enough, both firms will not offer bundles to customers. However, when $c_{v}$ is moderately large, only one firm offers bundles to customers. While when $c_{v}$ is relatively low, both firms offer bundles to customers, and the equilibrium strategy is (B, B). For numerical example with $k=3$, $t=1, M=9, n=10$ and $\bar{W}=1$, the effect of changing $c_{v}$ on final strategy equilibrium is shown in Figure 3.

The values of $c_{v}^{*}(k, t)$ and $c_{v}^{* *}(k, t)$ in Proposition 5 can be found in Figure 3. When $c_{v}>c_{v}^{* *}(k, t)$, $\Delta_{1}<0$ and $\Delta_{2}>0$. In this situation, if any firm offers bundles rather than products alone, it will only earn a lower profit no matter what strategy its rival takes. Therefore, both firms prefer to offer products alone to customers. When $c_{v}^{*}(k, t) \leq c_{v} \leq c_{v}^{* *}(k, t), \Delta_{1} \geq 0$ and $\Delta_{2} \geq 0$, if any one firm offers products alone, the other firm will prefer to offer bundles to customers. Consequently, the equilibrium is $(\mathrm{B}, \mathrm{P})$ or $(\mathrm{P}, \mathrm{B})$. When $c_{v}<c_{v}^{*}(k, t)$, if any firm offers products alone, the 


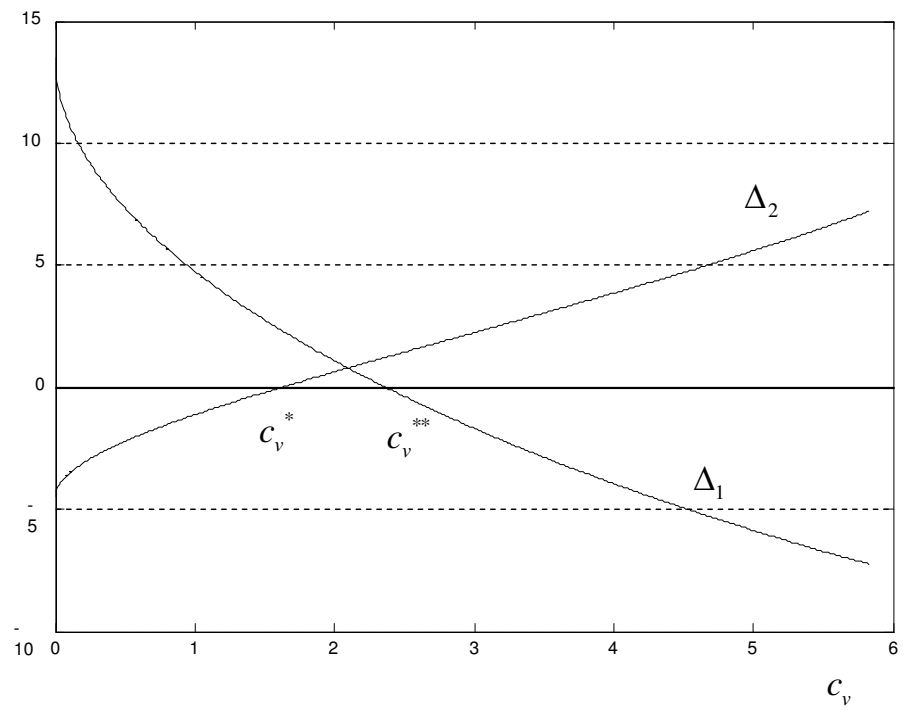

Figure 3: Service Bundling Strategies and Unit Service Capacity Cost

other firm prefers to offer bundles since $\pi_{1}^{<B, P>}=\pi_{2}^{<P, B>}>\pi_{1}^{<P, P>}=\pi_{2}^{<P, P>}$; while if any firm offers bundles, the other firm would not like to offer products alone to customers because $\pi_{1}^{<P, B>}=\pi_{2}^{<B, P>}>\pi_{1}^{<B, B>}=\pi_{2}^{<B, B>}$. Thus, the final equilibrium turns out to be (B, B), and two firms' profits are equal, i.e., $\pi_{1}^{<B, B>}=\pi_{2}^{<B, B>}$.

\section{$5 \quad$ Numerical Studies}

In this section, we report the results of our numerical studies, in which we investigate the effects of service sensitivity, firms difference, market size and service requirement rate on the final equilibrium. In these numerical studies, the model parameters are set to the following unless otherwise stated: $c_{v}=1, k=3, t=1, M=9, n=10$ and $\bar{W}=1$.

\subsection{Impact of the service sensitivity}

To understand the effect of service sensitivity parameter $k$ on the final equilibrium strategy, we illustrate the relationship between $\Delta_{1}, \Delta_{2}$ and $k$ in Figure 4 . We can observe that as $k$ increases, $\Delta_{1}$ increases and $\Delta_{2}$ decreases. Besides, there are two threshold values $k^{*}$ and $k^{* *}$ of the service level sensitivity such that: (i) when the service level sensitivity is low $\left(k<k^{*}\right), \Delta_{1}<0$ and $\Delta_{2}>0$, both firms offer products alone to customers, and the final equilibrium strategy is (P, P); (ii) when the service level sensitivity is moderately high $\left(k^{*}<k<k^{* *}\right), \Delta_{1}>0$ and $\Delta_{2}>0$, only one firm offers bundles and the other firm offers products, and the final equilibrium is $(\mathrm{B}, \mathrm{P})$ or $(\mathrm{P}, \mathrm{B})$; (iii) 


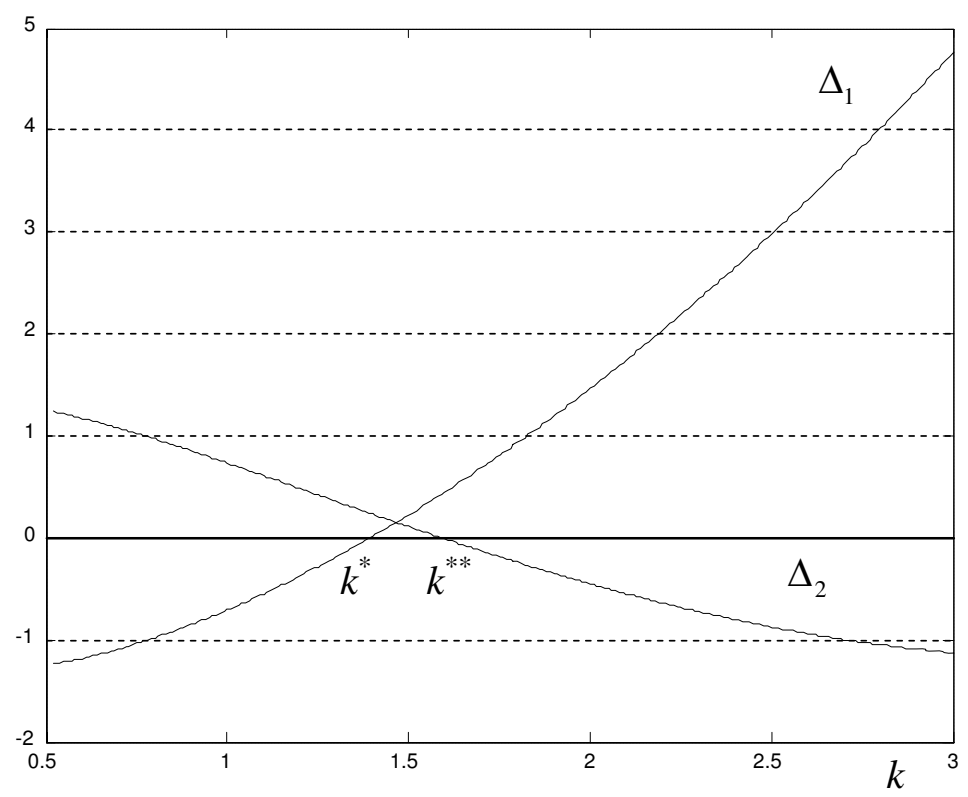

Figure 4: Service Bundling Strategies and Sensitivity of Service

when the service level sensitivity is high $\left(k>k^{* *}\right), \Delta_{1}>0$ and $\Delta_{2}<0$, both firms offer bundles, and the final equilibrium is (B, B). As $k$ refers to the importance of service to customers, it is easy to understand that when $k$ increases, offering bundles becomes a more competitive choice. This result is very intuitive. When we consider products such as shoes, it is not likely that the sensitivity to shoes maintenance service is high for many consumers, and we seldom see shoes companies offer maintenance service bundles. Besides, we can observe that $(\mathrm{B}, \mathrm{B})$ or $(\mathrm{P}, \mathrm{P})$ are the final equilibrium strategies for a wide range of parameter values.

\subsection{Impact of the firms difference}

We test the relationship between $\Delta_{1}, \Delta_{2}$ and the difference parameter $t$ under different parameter space of unit service capacity $\operatorname{cost} c_{v}$. The results are presented in Figure 5.

It can be observed from all plots in Figure 5 that both $\Delta_{1}$ and $\Delta_{2}$ are decreasing in $t$, and the decreasing speed gradually slows down. Since $t$ represents the difference between two firms' products, as $t$ increases, there are less intensive competition between the two firms, thus the profits of two firms depend more on their own cost structure and the value of products. Hence, both $\Delta_{1}$ and $\Delta_{2}$ converge to a stable value as $t$ increases. Furthermore, plot(a) shows the relationship between $\Delta_{1}, \Delta_{2}$ and $t$ when the unit service capacity cost is low $\left(c_{v}<c_{v}^{*}\right)$. As $t$ increases, $\Delta_{1}$ and $\Delta_{2}$ decrease, but $\Delta_{1}$ remains positive and $\Delta_{2}$ remains negative. Thus the final equilibrium is still 

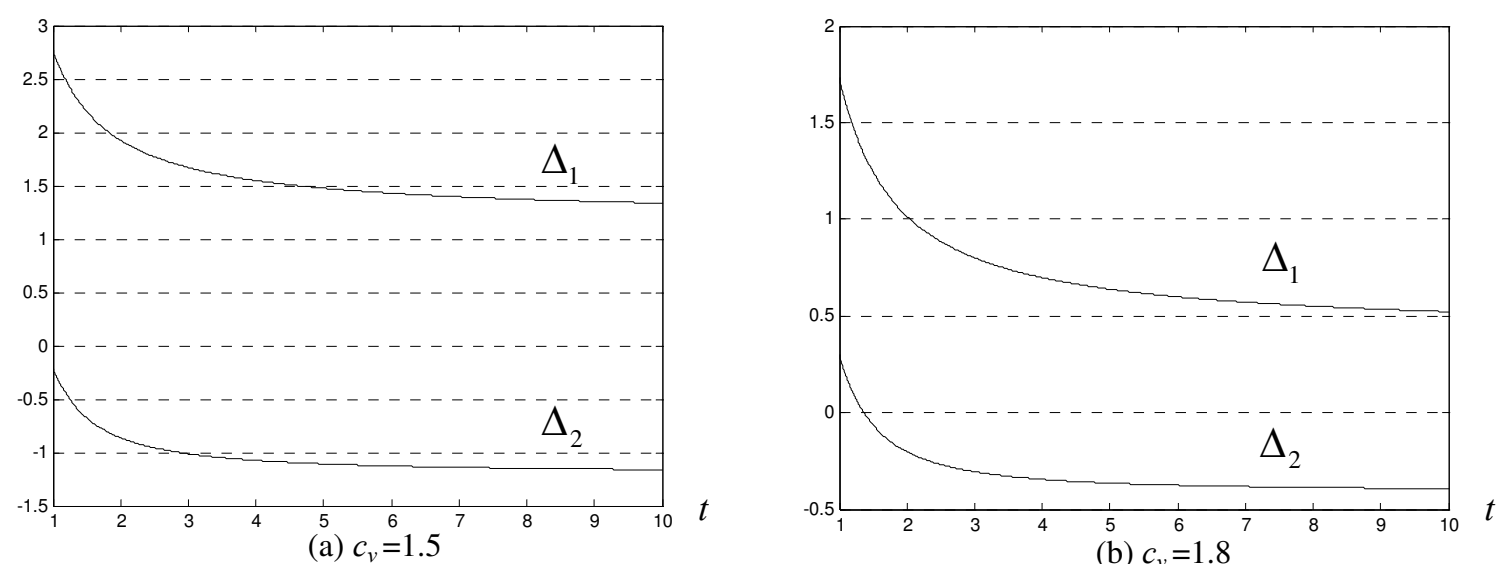

(b) $c_{v}=1.8$
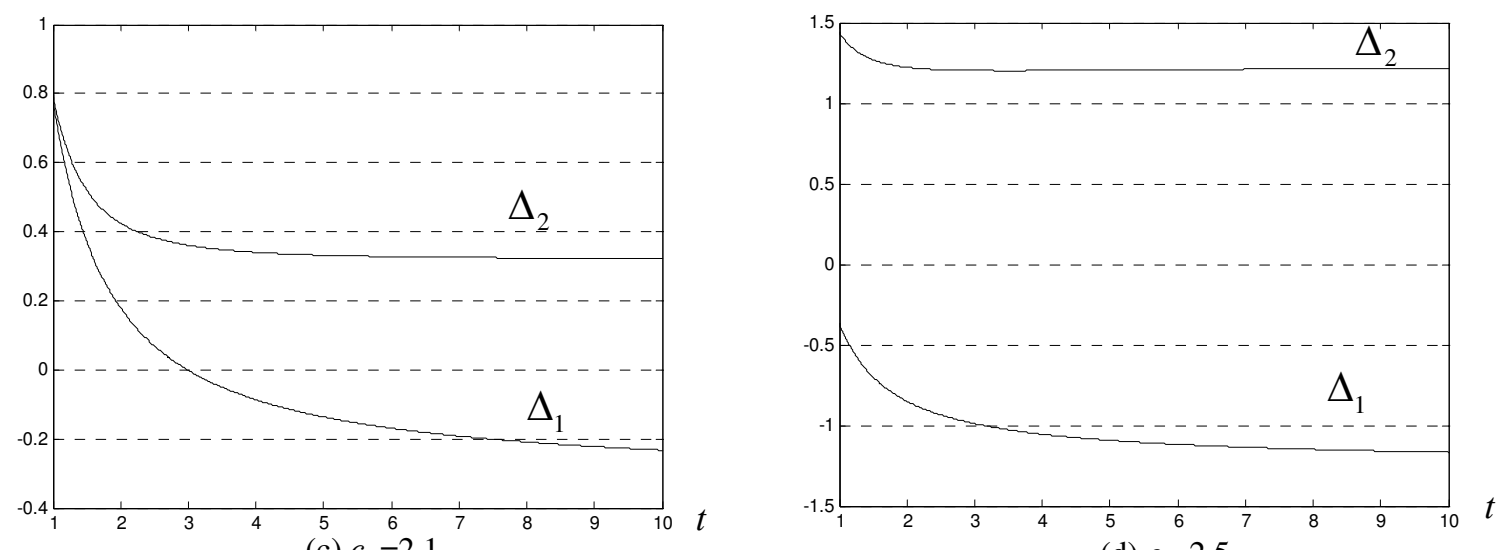

(d) $c_{v}=2.5$

Figure 5: Service Bundling Strategies and Firms Difference

(B, B). Plot(b) shows the relationship between $\Delta_{1}, \Delta_{2}$ and $t$ when the unit service capacity cost is moderately low $\left(c_{v}^{*}<c_{v}<c_{v}^{* *}\right)$. As $t$ increases, $\Delta_{1}$ decreases from a positive value to a negative value, while $\Delta_{2}$ remains positive. The final equilibrium changes from (B, P) to (B, B). When the unit service capacity cost is moderately high $\left(c_{v}^{*}<c_{v}<c_{v}^{* *}\right)$, e.g. see plot(c), $\Delta_{1}$ decreases from a positive value to a negative value, while $\Delta_{2}$ keeps positive. The final strategy equilibrium changes from $(\mathrm{B}, \mathrm{P})$ to $(\mathrm{P}, \mathrm{P})$. In $\operatorname{plot}(\mathrm{d})$, where the unit service capacity cost is high $\left(c_{v}>c_{v}^{* *}\right)$, as $t$ increases, $\Delta_{1}$ and $\Delta_{2}$ decrease, but $\Delta_{1}$ remains negative and $\Delta_{2}$ remains positive, and the final equilibrium $(\mathrm{P}, \mathrm{P})$ does not change.

Figure 5 indicates that as $t$ increases, the final strategy equilibrium is more likely to be $(\mathrm{B}, \mathrm{B})$ or $(\mathrm{P}, \mathrm{P})$ than $(\mathrm{B}, \mathrm{P})$. As the difference between two firms' products reduces the competition, both firms tend to be more like monopolies. Thus they are more likely to take the same strategy due to the symmetric structure. In consistent with the observations in Section 5.1 and Section 5.2, (B, B) 


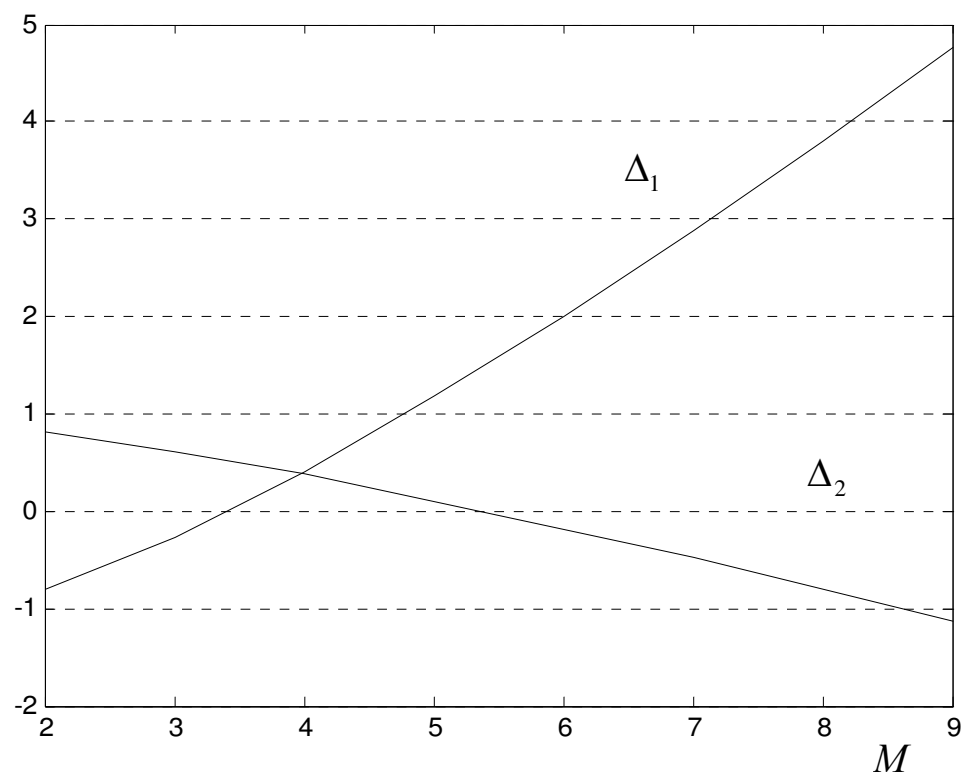

Figure 6: Service Bundling Strategies and Market Size

and $(\mathrm{P}, \mathrm{P})$ are the final equilibrium strategies for a wide range of parameter values.

\subsection{Impact of the market size}

The relationship between $\Delta_{1}, \Delta_{2}$ and the market size $M$ is shown in Figure 6 .

Figure 6 shows that as $M$ increases, $\Delta_{1}$ increases and $\Delta_{2}$ decreases. We can observe that there are two threshold values $M^{*}$ and $M^{* *}$ of the market size such that: (i) when the market size is small $\left(M<M^{*}\right), \Delta_{1}<0$ and $\Delta_{2}>0$, both firms offer products alone to customers, and the final equilibrium strategy is $(\mathrm{P}, \mathrm{P})$; (ii) when the market size is moderately big $\left(M^{*}<M<M^{* *}\right)$, $\Delta_{1}>0$ and $\Delta_{2}>0$, one firm offers bundles and the other firm offers products alone to customers, the final equilibrium is $(\mathrm{B}, \mathrm{P})$ or $(\mathrm{P}, \mathrm{B})$; (iii) when the market size is relatively big $\left(M>M^{* *}\right)$, $\Delta_{1}>0$ and $\Delta_{2}<0$, both firms offer bundles to customers, and the final equilibrium is (B, B). These observations are easy to understand: as the market size increases, the fixed cost for the service capacity can be shared by more customers, thus both firms have more incentives to offer bundles. 


\subsection{Impacts of service requirements arrival rate}

Note that the customers'service requirements arrival rate $\lambda_{i}$ is proportional to the demand $D_{i}$ and $\frac{1}{n}$ is the average usage rate of all customers. We can check the impacts of service rate by checking the impacts of $n$. The relationship between $\Delta_{1}, \Delta_{2}$ and the service requirement rate $n$ is shown in Figure 7.

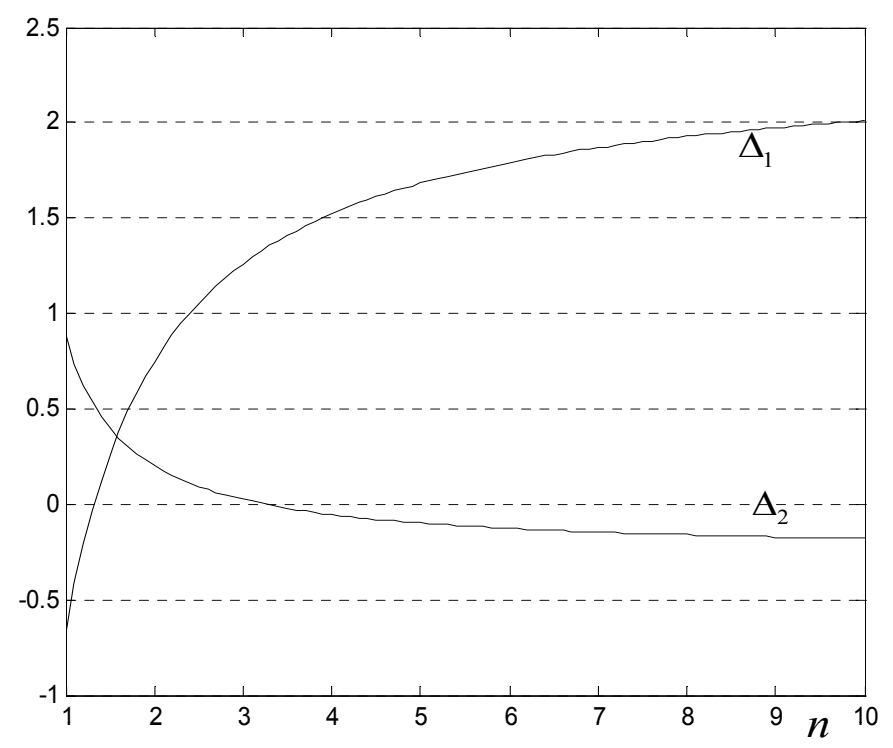

Figure 7: Service Bundling Strategies and Service Requirement Rate

Figure 7 shows that $\Delta_{1}$ is increasing in $n$ and $\Delta_{2}$ is decreasing in $n$. Besides, we can observe: when $n$ is low, $\Delta_{1}<0$ and $\Delta_{2}>0$, both firms offer products alone to customers; when $n$ is moderately high, $\Delta_{1}>0$ and $\Delta_{2}>0$, only one firm offers bundles and the other firm offers products; when $n$ is high, $\Delta_{1}>0$ and $\Delta_{2}<0$, both firms offer bundles. These observations are intuitive. As $1 / n$ determines the service arrival rate, when $n$ is small, customers are more likely to ask for service requirement. In this situation, bundles providers have to invest more on service facility, which leads to a high service cost. Thus firms are less likely to offer service bundles. For example, we seldom see auto companies provide car washing service bundles. 


\section{Conclusion}

This paper studies the service bundling strategies of two firms in a competing environment. First, we analyze the optimal price and service level decisions under different sub-games. We find that a firm will offer a higher service level and charge a higher price when only one firm offers bundles compared to the case when both two firms offer bundles. Second, we show that as the market size increases, the bundles providers intend to offer a higher service level due to the scale economy of service capacity investment. Third, we characterize the market conditions in which only one firm, or both firms offer od do not offer P\&S bundles. We find that in equilibrium, whether firms would like to offer bundles or products alone depends on the cost structure of the service and customers' sensitivity to service. Our analysis also shows that when the service capacity cost is relatively low (high), both firms offer bundles (products alone) to customers; when the service capacity cost is moderately large, only one firm offers bundles and the other firm offers products alone. Finally, we conduct several numerical experiments to show the impacts of different parameters on the final equilibrium strategy. Our results suggest that offering bundles becomes a more competitive choice for both firms when customers' sensitivity to service is high or market size is large.

The model can be further extended in our future work. We assume that all customers' sensitivity to the service are the same, i.e., $k$ is indifferent between customers. Relaxing this assumption may lead to more insights and interesting observations. Furthermore, we do not consider the competition in the service market. As the rapid growth in the outsourcing industry provides more market gain for companies offering additional service, our future research could also investigate the competition between bundles providers and the third service providers.

\section{Acknowledgments}

This research was supported by the Natural Science Foundation of China (Nos. 70701029, 70433003), the Fundamental Research Funds for the Central Universities of China, the Research Fund for the Doctoral Program of Higher Education of China (No. 20070968063) and State-Sponsored Study Abroad Program of China(CSC). 


\section{Appendix}

\section{Proof of Proposition 2}

For equations (11) and (12), using first order conditions, we can get:

$$
\begin{aligned}
& \frac{\partial \pi_{1}^{<B, P>}}{\partial W_{1}}=-\frac{1}{9} \frac{3 k M\left(W_{2}\right)^{2} t-k^{2} M\left(W_{2}\right)^{3}+k^{2} M\left(W_{2}\right)^{2} W_{1}-9 c_{v} t}{\left(W_{2}\right)^{2} t}=0 \\
& \frac{\partial \pi_{2}^{<B, P>}}{\partial W_{2}}=-\frac{1}{9} \frac{3 k M\left(W_{1}\right)^{2} t-k^{2} M\left(W_{1}\right)^{3}+k^{2} M\left(W_{1}\right)^{2} W_{2}-9 c_{v} t}{\left(W_{1}\right)^{2} t}=0 .
\end{aligned}
$$

By solving the above equations, we obtain $\left(W_{1}-W_{2}\right)\left[W_{1}\left(\frac{3 t}{k}-W_{2}\right)+W_{1}\left(\frac{3 t}{k}-W_{2}\right)\right]=0$. From condition $\bar{W}<\frac{3 t}{k}$, we get $W_{1}\left(\frac{3 t}{k}-W_{2}\right)+W_{1}\left(\frac{3 t}{k}-W_{2}\right)>0$. Thus $W_{1}-W_{2}=0$. By subtracting $W_{1}=W_{2}$ into (31) and (32), we can derive the equilibrium solutions: $W_{1}^{<B, P>}=$ $W_{1}^{<B, P>}=\sqrt{\frac{3 c_{v}}{k M}}$. By substituting $W_{1}^{<B, P>}$ and $W_{1}^{<B, P>}$ into (2), (9), (10), (11) and (12), we can derive other equilibrium solutions .

\section{Proof of Lemma 1}

Let $G(x)=x^{2}\left(\frac{3 t-\frac{c_{v}}{n}}{k}+\bar{W}-x\right)$, we have $G(0)=0<\frac{9 c_{v} t}{M k^{2}}$. From the condition $k(\bar{W}-$ $\left.\sqrt{\frac{3 c_{v}}{k M}}\right) \geq \frac{c_{v}}{n}$, we have $\bar{W}-\frac{c_{v}}{k n} \geq \sqrt{\frac{3 c_{v}}{k M}}$, thus $G\left(\bar{W}-\frac{c_{v}}{k n}\right)=\left(\bar{W}-\frac{c_{v}}{k n}\right)^{2} \frac{3 t}{k}>\frac{9 c_{v} t}{M k^{2}}$. In addition, $G(x)$ is a continuous function, hence we can conclude that there exists at least one solution in $\left[0, \bar{W}-\frac{c_{v}}{k n}\right]$ for equation (1).

For the uniqueness, by using condition $\frac{3 t}{k}>\bar{W}$, we have:

$G^{\prime}(x)=2\left(\frac{3 t-\frac{c_{v}}{n}}{k}+\bar{W}\right) x-x^{2}>2\left(2 \bar{W}-\frac{c_{v}}{k n}\right) x-x^{2}>0, \forall x \in\left[0, \bar{W}-\frac{c_{v}}{k n}\right]$.

Thus $G(x)$ is monotonic increasing in $\left[0, \bar{W}-\frac{c_{v}}{k n}\right]$, which guarantees the uniqueness of solution. 


\section{Proof of Corollary 1:}

From Lemma 1, we know that $W_{1}^{<B, P>}$ is a function of $c_{v}$, which is determined by equation (26). By differentiating both sides of equation (26) with respect to $c_{v}$, we have:

$$
\frac{\partial W_{1}^{<B, P>}}{\partial c_{v}}=\frac{k M\left(W_{1}^{<B, P>}\right)^{2}+9 t n}{k M W_{1}^{<B, P>}\left(-3 n k W_{1}^{<B, P>}+2 n k \bar{W}+6 t n-2 c_{v}\right)}
$$

Rewriting the denominator of the right hand side of equation (33), we have:

$$
\begin{aligned}
& -3 n k W_{1}^{<B, P>}+2 n k \bar{W}+6 t n-2 c_{v} \\
& =\operatorname{tn}\left(\frac{-3 k W_{1}^{<B, P>}}{t}+\frac{2 k \bar{W}}{t}+6-\frac{2 c_{v}}{t n}\right) \\
& >\operatorname{tn}\left(\frac{2 c_{v}}{t n}-\frac{2 k W_{1}^{<B, P>}}{t}+6-\frac{2 c_{v}}{t n}\right) \\
& >\operatorname{tn}\left(6-\frac{2 k \bar{W}}{t}\right) \\
& >0
\end{aligned}
$$

Where the first inequality follows from condition $k\left(\bar{W}-W_{1}\right)>\frac{c_{v}}{n}$, the second one from $W_{1}^{<B, P>}<\bar{W}$ and the last one from $\bar{W}<\frac{3 t}{k}$. Thus we have $\frac{\partial W_{1}^{<B, P>}}{\partial c_{v}}>0$.

The results of $\frac{\partial W_{1}^{<B, P>}}{\partial t}>0, \frac{\partial W_{1}^{<B, P>}}{\partial k}<0$ and $\frac{\partial W_{1}^{<B, P>}}{\partial M}>0$ can be abtained following similar logic.

\section{Proof of Corollary 2:}

From the condition $W_{1}^{<B, P>} \in\left[0, \bar{W}-\frac{c_{v}}{k n}\right]$, we have $1-\frac{c_{v}}{3 n t}+\frac{k\left(\bar{W}-W_{1}^{<B, P>}\right)}{3 t} \geq 1$. As $W_{1}^{<B, P>}$ is the solution of equation (26), thus we have

$$
\left(W_{1}^{<B, P>}\right)^{2}=\frac{\frac{3 c_{v} t}{k M}}{1-\frac{c_{v}}{3 n t}+\frac{k\left(\bar{W}-W_{1}^{<B, P>}\right)}{3 t}} \leq \frac{3 c_{v} t}{k M}=\left(W_{1}^{<B, B>}\right)^{2}
$$

which leads to $W_{1}^{<B, P>} \leq W_{1}^{<B, B>}$. 


\section{Proof of Corollary 3:}

As $p_{1}^{<B, P>}=c+t+\frac{2 c_{v}}{3 n}+\frac{k\left(\bar{W}-W_{1}^{<B, P>}\right)}{3 t}$, by differentiating $p_{1}^{<B, P>}$ with respect to $k$, we have:

$$
\frac{\partial p_{1}^{<B, P>}}{\partial k}=\frac{\bar{W}-W_{1}^{<B, P>}}{3 t}-\frac{k\left(\frac{\partial W_{1}^{<B, P>}}{\partial k}\right)}{3 t}
$$

From Corollary 1, we have $\frac{\partial W_{1}^{<B, P>}}{\partial k}<0$, hence $\frac{\partial p_{1}^{<B, P>}}{\partial k}>0$.

The proof of $\frac{\partial p_{2}^{<B, P>}}{\partial k}<0$ and $\frac{\partial p_{2}^{<B, P>}}{\partial c_{v}}>0$ can be show following similar logic.

\section{Proof of Corollary 4:}

It is easy to see that $p_{1}^{<B, B>}=p_{2}^{<B, B>}>p_{1}^{<P, P>}=p_{2}^{<P, P>}$. From Corollary 2 we know $W_{1}^{<B, P>} \leq W_{1}^{<B, B>}$. Using condition $k\left(\bar{W}-W_{1}^{<B, B>}\right)>\frac{c_{v}}{n}$, we have $k\left(\bar{W}-W_{1}^{<B, P>}\right) \geq$ $k\left(\bar{W}-W_{1}^{<B, B>}\right)>\frac{c_{v}}{n}$. Thus we have $p_{1}^{<B, P>}=c+t+\frac{2 c_{v}}{3 n}+\frac{k\left(\bar{W}-W_{1}^{<B, P>}\right)}{3 t}>c+t+\frac{c_{v}}{n}=$ $p_{1}^{<B, B>}$ and $p_{2}^{<B, P>}=c+t+\frac{c_{v}}{3 n}-\frac{k\left(\bar{W}-W_{1}^{<B, P>}\right)}{3 t}>c+t=p_{2}^{<B, B>}$.

From the assumption $k\left(\bar{W}-\sqrt{\frac{3 c_{v}}{k M}}\right) \geq \frac{c_{v}}{n}$, we can see that $c_{v} \in\left[0, \overline{c_{v}}\right]$.

\section{Proof of Corollary 5:}

From equation (17), we can see that:

$$
D_{1}^{<B, P>}=\left[\frac{k\left(W-W_{1}^{<B, P>}\right)}{3}-\frac{c v}{3 n}+t\right] \frac{M}{2 t} .
$$

From Lemma 1 , we have $W_{1}^{<B, P>}<W-\frac{c v}{k n}$. Thus $D_{1}^{<B, P>} \geq \frac{M}{2}$, and $D_{2}^{<B, P>}=M-$ $D_{1}^{<B, P>} \leq \frac{M}{2}$. Since we have $D_{1}^{<B, B>}=D_{2}^{<B, B>}>D_{1}^{<P, P>}=D_{2}^{<P, P>}$, thus the result holds. 


\section{Proof of Lemma 2}

From Propositions 1, 2 and 3, we further rewrite $\Delta_{1}\left(c_{v}\right)$ and $\Delta_{2}\left(c_{v}\right)$ as follows:

$$
\begin{gathered}
\Delta_{1}\left(c_{v}\right)=\frac{M t}{2}\left[1-\frac{c_{v}}{3 n t}+\frac{k\left(\bar{W}-W_{1}^{<B, P>}\right)}{3 t}\right]^{2}-\frac{c_{v}}{W_{1}^{<B, P>}}-\frac{M t}{2} \\
\Delta_{2}\left(c_{v}\right)=\frac{M t}{2}\left[1+\frac{c_{v}}{3 n t}-\frac{k\left(\bar{W}-W_{1}^{<B, P>}\right)}{3 t}\right]^{2}-\left(\frac{M t}{2}-\sqrt{\frac{c_{v} k M}{3}}\right)
\end{gathered}
$$

\section{Proof of Lemma 2-(i)}

To prove Lemma 2-(i), it is sufficient to prove that $\Delta_{1}\left(c_{v}\right)$ is increasing in $c_{v}$, (ii) $\Delta_{1}(0)>0$ and $\Delta_{1}\left(\overline{c_{v}}\right)<0$. Firstly, we prove that $\Delta_{1}\left(c_{v}\right)$ is increasing in $c_{v}$. Evaluating the derivatives of $\Delta_{1}\left(c_{v}\right)$ with respect to $c_{v}$ we have the following equations:

$$
\begin{aligned}
& \frac{\partial \Delta_{1}\left(c_{v}\right)}{\partial c_{v}}=M t\left[1-\frac{c_{v}}{3 n t}+\frac{k\left(\bar{W}-W_{1}^{<B, P>}\right)}{3 t}\right]\left(-\frac{1}{3 n t}-\frac{k \frac{\partial W_{1}^{<B, P>}}{\partial c_{v}}}{3 t}\right)+\frac{c_{v} \frac{\partial W_{1}^{<B, P>}}{\partial c_{v}}}{\left(W_{1}^{<B, P>}\right)^{2}}-\frac{1}{W_{1}^{<B, P>}} \\
& =\left[M t\left(1-\frac{c_{v}}{3 n t}+\frac{k\left(\bar{W}-W_{1}^{<B, P>}\right)}{3 t}\right)\left(-\frac{k}{3 t}\right)+\frac{c_{v}}{\left(W_{1}^{<B, P>}\right)^{2}}\right] \frac{\partial W_{1}^{<B, P>}}{\partial c_{v}} \\
& +M t\left[1-\frac{c_{v}}{3 n t}+\frac{k\left(\bar{W}-W_{1}^{<B, P>}\right)}{3 t}\right]\left(-\frac{1}{3 n t}\right)-\frac{1}{W_{1}^{<B, P>}} \\
& \text { As } M t\left[1-\frac{c_{v}}{3 n t}+\frac{k\left(\bar{W}-W_{1}^{<B, P>}\right)}{3 t}\right]\left(-\frac{k}{3 t}\right)+\frac{c_{v}}{\left(W_{1}^{<B, P>}\right)^{2}}=0 \text {, thus we have } \\
& \frac{\partial \Delta_{1}\left(c_{v}\right)}{\partial c_{v}}=M t\left(1-\frac{c_{v}}{3 n t}+\frac{k\left(\bar{W}-W_{1}^{<B, P>}\right)}{3 t}\right)\left(-\frac{1}{3 n t}\right)-\frac{1}{W_{1}^{<B, P>}}<0 .
\end{aligned}
$$

which shows that $\Delta_{1}\left(c_{v}\right)$ is monotonic decreasing in $c_{v}$.

Now we prove that $\Delta_{1}(0)>0$ and $\Delta_{1}\left(\overline{c_{v}}\right)<0$. It can be directly found that $\Delta_{1}(0)=$ $\frac{M t}{2}\left[1+\frac{k\left(\bar{W}-W_{1}^{<B, P>}\right)}{3 t}\right]^{2}-\frac{M t}{2}>0$. For $\Delta_{1}\left(\overline{c_{v}}\right)$, as $\overline{c_{v}}$ is the solution of $k\left(\bar{W}-\sqrt{\frac{3 c_{v}}{k M}}\right)=$ 
$\frac{c_{v}}{n}$, by solving the equation $\left(W_{1}^{<B, P>}\right)^{2}\left[\frac{3 t-\frac{\overline{c_{v}}}{n}}{k}+\left(\bar{W}-W_{1}^{<B, P>}\right)\right]-\frac{9 \overline{c_{v}} t}{M k^{2}}=0$, we can get $W_{1}^{<B, P>}=\sqrt{\frac{3 \overline{c_{v}}}{k M}}$. Subscribing $W_{1}^{<B, P>}$ into equation (34), and we get $\Delta_{1}\left(\overline{c_{v}}\right)=-\sqrt{\frac{\overline{c_{v}} k M}{3}}<0$.

Furthermore, as $\Delta_{1}\left(c_{v}\right)$ is a continuous function, we can conclude that Lemma2-(i) holds. Besides, we can see that $c_{v}^{* *}$ is the value where $\Delta_{1}\left(c_{v}^{* *}\right)=0$.

\section{Proof of Lemma 2-(ii)}

To prove Lemma 2-(i), we first show that $\Delta_{2}\left(c_{v}\right)$ is increasing in $c_{v}$, and then show that $\Delta_{2}(0)<0$ and $\Delta_{2}\left(\overline{c_{v}}\right)>0$.

From equation (26), we can see that $1-\frac{c_{v}}{3 n t}+\frac{k\left(\bar{W}-W_{1}^{<B, P>}\right)}{3 t}>0$. Combined with the condition $\frac{\partial W_{1}^{<B, P>}}{\partial c_{v}}$ from Corollary 2, we can find that $\frac{M t}{2}\left[1+\frac{c_{v}}{3 n t}-\frac{k\left(\bar{W}-W_{1}^{<B, P>}\right)}{3 t}\right]^{2}$ is increasing in $c_{v}$. Thus $\Delta_{2}\left(c_{v}\right)=\frac{M t}{2}\left[1+\frac{c_{v}}{3 n t}-\frac{k\left(\bar{W}-W_{1}^{<B, P>}\right)}{3 t}\right]^{2}-\left(\frac{M t}{2}-\sqrt{\frac{c_{v} k M}{3}}\right)$ is increasing in $c_{v}$.

Using the similar logic in the proof of Lemma2-(i), we can also prove: $\Delta_{2}(0)=\frac{M t}{2}[1-$ $\left.\frac{k\left(\bar{W}-W_{1}^{<B, P>}\right)}{3 t}\right]^{2}-\frac{M t}{2}<0$ and $\Delta_{2}\left(\overline{c_{v}}\right)=\sqrt{\frac{\overline{c_{v}} k M}{3}}>0$.

As $\Delta_{2}\left(c_{v}\right)$ is a continuous function, thus we can conclude that Lemma 2-(ii) holds. So the result of Lemma 2-(ii) follows. And we can see that $c_{v}^{*}$ is the value where $\Delta_{2}\left(c_{v}^{*}\right)=0$.

\section{Proof of Lemma 2-(iii)}

From proof of Lemma 2-(i) we know that $\Delta_{1}\left(c_{v}\right)$ is monotonic decreasing in $c_{v}$ and $\Delta_{1}\left(c_{v}^{* *}\right)=0$. Thus to prove $c_{v}^{*} \leq c_{v}^{* *}$, it is sufficient to prove that $\Delta_{1}\left(c_{v}^{*}\right)>\Delta_{1}\left(c_{v}^{* *}\right)=0$.

Let $S\left(c_{v}\right)=\frac{k\left(\bar{W}-W_{1}^{<B, P>}\right)}{3 t}-\frac{c_{v}}{3 n t}$. Using condition $W_{1}^{<B, P>} \in\left(0, \bar{W}-\frac{c_{v}}{k n}\right]$ and $\bar{W}<\frac{3 t}{k}$, we can see that $S\left(c_{v}\right) \in(0,1]$. Hence $\Delta_{1}\left(c_{v}\right)$ and $\Delta_{2}\left(c_{v}\right)$ can be simplified as

$$
\Delta_{1}\left(c_{v}\right)=\frac{M t}{2}\left[S\left(c_{v}\right)^{2}+2 S\left(c_{v}\right)\right]-\frac{c_{v}}{W_{1}^{<B, P>}}
$$


$\Delta_{2}\left(c_{v}\right)=\frac{M t}{2}\left[S\left(c_{v}\right)^{2}-2 S\left(c_{v}\right)\right]+\sqrt{\frac{c_{v} k M}{3}}$

And the equation (26) can be simplified as $\left(W_{1}^{<B, P>}\right)^{2}\left[1+S\left(c_{v}\right)\right]-\frac{3 c_{v}}{k M}=0$, which leads to $W_{1}^{<B, P>}=\sqrt{\frac{3 c_{v}}{k M\left[1+S\left(c_{v}\right)\right]}}$. Thus $\Delta_{1}\left(c_{v}^{*}\right)$ is derived by:

$$
\Delta_{1}\left(c_{v}^{*}\right)=\frac{M t}{2}\left[S\left(c_{v}^{*}\right)^{2}+2 S\left(c_{v}^{*}\right)\right]-\sqrt{\frac{c_{v} k M\left[1+S\left(c_{v}^{*}\right)\right]}{3}} .
$$

As we know $c_{v}^{*}$ is the value where $\Delta_{2}\left(c_{v}^{*}\right)=0$, we have $\Delta_{2}\left(c_{v}^{*}\right)=\frac{M t}{2}\left[S\left(c_{v}^{*}\right)^{2}-2 S\left(c_{v}^{*}\right)\right]+$ $\sqrt{\frac{c_{v} k M}{3}}=0$, in turn $\sqrt{\frac{c_{v} k M}{3}}=\frac{M t}{2}\left[2 S\left(c_{v}^{*}\right)-S\left(c_{v}^{*}\right)^{2}\right]$. Thus (36) can be rewritten as:

$$
\begin{aligned}
& \Delta_{1}\left(c_{v}^{*}\right)=\frac{M t}{2}\left[S\left(c_{v}^{*}\right)^{2}+2 S\left(c_{v}^{*}\right)\right]-\frac{M t}{2}\left[2 S\left(c_{v}^{*}\right)-S\left(c_{v}^{*}\right)^{2}\right] \sqrt{\left[1+S\left(c_{v}^{*}\right)\right]}() \\
& =\frac{M t}{2} S\left(c_{v}^{*}\right)\left[\left(S\left(c_{v}^{*}\right)+2\right)-\left(2-S\left(c_{v}^{*}\right)\right) \sqrt{\left[1+S\left(c_{v}^{*}\right)\right]}\right] .
\end{aligned}
$$

If $\left(S\left(c_{v}^{*}\right)+2\right)>\left(2-S\left(c_{v}^{*}\right)\right) \sqrt{\left[1+S\left(c_{v}^{*}\right)\right]}$, then $\Delta_{1}\left(c_{v}^{*}\right)>0$ holds. As $S\left(c_{v}\right) \in(0,1]$, we square both sides of the inequality and get:

$$
4+4 S\left(c_{v}^{*}\right)+S\left(c_{v}^{*}\right)^{2}>4-3 S\left(c_{v}^{*}\right)^{2}+S\left(c_{v}^{*}\right)^{3}
$$

(37) obviously holds as $S\left(c_{v}\right) \in(0,1]$. Thus we have $\Delta_{1}\left(c_{v}^{*}\right)>0=\Delta_{1}\left(c_{v}^{* *}\right)$. As $\Delta_{1}\left(c_{v}\right)$ is increasing in $c_{v}$ for $c_{v} \in(0,1]$, combined with conditions $c_{v}^{*} \in\left(0, \overline{c_{v}}\right]$ and $c_{v}^{* *} \in\left[0, \overline{c_{v}}\right]$, we can conclude that $c_{v}^{*}<c_{v}^{* *}$.

So the results of Lemma 2 follow.

\section{Proof of Proposition 5}

The results of Proposition 5 can be directly deduced from Lemma 2 .

\section{References}

[1] Allon, G., A. Federgruen. 2007. Competition in service industries. Operations Research, 55(1), $37-55$.

[2] Allon, G., A. Federgruen. 2008. Service competition with general queueing facilities. Operations Research, 56(4), 827C849. 
[3] Carbajo J., DeMeza D., and Seidmann D. J., 1990. A Strategic Motivation for Commodity Bundling. Journal of Industrial Economics, 38, 283-298.

[4] Chen Y., 1997. Equilibrium product bundling. Journal of Business, 70 (1), 85-103.

[5] Chen, H., Y-W. Wan. 2000. Price and capacity competition of make-to order firms. Working Paper.

[6] Cohen M.A., S. Whang. 1997. Competing in Product and Service: A Product Life Cycle Model. Management Science, 43(4), 535-545.

[7] Daniel M. B. 2001. Product Differentiation, Competition, and International Trade. The Canadian Journal of Economics, 34(4), 1010-1023.

[8] Fan, M., Kumara, S., Whinston, A.B. 2009. Short-term and long-term competition between providers of shrink-wrap software and software as a service. European Journal of Operational Research, 196 (2), 661-671.

[9] Herrmann, A., Huber, F., Coulter, R.H., 1997. Product and service bundling decisions and their effects on purchase intention. Pricing Strategy \& Practice, 5 (3), 99-104.

[10] Kameshwaran, S., Viswanadham, N., Desai, V. 2009. Bundling and pricing of product with after-sales services. International Journal of Operational Research 6(1), 92-109.

[11] Kurata, H., Nam, S. 2010. After-sales service competition in a supply chain: Optimization of customer satisfaction level or profit or both? International Journal of Production Economics, $127,136-146$.

[12] Luski, I. 1976. On partial equilibrium in a queueing system with two servers. The Review of Economic Studies, 43, 519-525.

[13] Levhari, D., I. Luski, 1978. Duopoly pricing and waiting lines. European Economic Review, $11,17-35$.

[14] Nalebuff, B., 2004. Bundling as an entry barrier. Quarterly Journal of Economics, 119, 159-187.

[15] Stigler, G. J., 1968. A Note on Block Booking. In G. J. Stigler (ed.), The Organization of Industries. Homewood, Ill.: Irwin.

[16] Stremersch, S., Tellis, G.J., 2002. Strategic bundling of products and prices: A new synthesis for marketing. Journal of Marketing, 66 (1), 55-72. 
[17] Tan, Y., Mookerjee, V.S., 2005. Allocating spending between advertising and information technology in electronic retailing. Management Science 51 (8), 1236-1249.

[18] Xiao T.J., D.Q. Yang. 2008. Price and service competition of supply chains with risk-averse retailers under demand uncertainty. International Journal of Production Economics, 114(2), $187-200$.

[19] Zhang, Z., Tan, Y., D. Dey. 2009. Price Competition with Service Level Guarantee in Web Services. Decision Support System, 47(2), 93-104. 